\title{
Characterization of the infiltration capacity of permeable pavements with porous asphalt surface using the CF Infiltrometer
}

Jorge Rodriguez-Hernandez ${ }^{1}$; Daniel Castro-Fresno ${ }^{2}$; Andrés H. Fernández-Barrera ${ }^{3}$; Ángel Vega-Zamanillo ${ }^{4}$

*Corresponding author: E: rodrighj@unican.es; T: +34 942203943; F. +34942201703

${ }^{1}$ Ph.D. M.Sc. Civil Engineer, Assistant Professor, GITECO, Departamento de Transportes y T. de P. y P. Universidad de Cantabria, ETSICCP, Avenida de los Castros s/n, 39005 Santander, Spain.

${ }^{2}$ Ph.D. M.Sc. Civil Engineer, Full Time Lecturer, GITECO, Departamento de Transportes y T. de P. y P., Universidad de Cantabria, ETSICCP, Avenida de los Castros s/n, 39005 Santander, Spain.

${ }^{3}$ Ph.D. Civil Engineer, Assistant Professor, Escuela de Ingeniería en Construcción, Facultad de Ingeniería, Pontificia Universidad Católica de Valparaíso, Avenida Brasil 2147, Valparaíso, Chile.

${ }^{4}$ Ph.D. M.Sc. Civil Engineer, Full Time Lecturer, Roads and Airports Group, Departamento de Transportes y T. de P. y P., Universidad de Cantabria, ETSICCP, Avenida de los Castros s/n, 39005 Santander, Spain

\section{Abstract}

Porous asphalt is used in Permeable Pavement Systems (PPS), but it is sensitive to surface clogging leading to a loss in its infiltration capacity. Test methods based on the use of permeable pavement models, manufactured in laboratory and assessed under different clogging conditions, slope, rain and runoff, have been widely applied to the study of permeable pavements with concrete blocks but not to the study of porous bituminous mixtures. The Cantabrian Fixed (CF) Infiltrometer has been used for the study of porous asphalt with void percentages between $20 \%$ and $33 \%$. Three clogging scenarios were studied: newly placed surface, surface with an average maintenance level and clogged surface. Each clogging scenario was tested with 5 different slopes: $0 \%, 2 \%, 5 \%, 8 \%$ and $10 \%$ and three repetitions. The direct rainfall simulation was produced by five lines of bubblers over the $0.25 \mathrm{~m}^{2}$ piece and the runoff was simulated by one perforated pipe over a plastic ramp at the beginning of the surface. From the analysis of the results, it was concluded that a suitable design of a porous bituminous mixture, with a void percentage that increases with depth, along with surface brushing are enough to ensure and maintain a good infiltration capacity. Finally, an empirical conservative model for estimating the porous asphalt infiltration capacity based on the length, the clogging scenario, and the surface slope, is proposed. 
Keywords: SUDS; PPS; porous asphalt; infiltration capacity; clogging.

\section{Introduction}

Porous asphalt can be used in Sustainable Drainage Systems (SUDS) or Low Impact Development (LID) as a surface for a Permeable Pavement System (PPS) to mitigate conventional large design storm flows (Pratt et al. 2002, Scholz and Grabowiecki 2007, Fassman and Blackbourn 2010). This was demonstrated in the United States for porous asphalt years ago (Grover et al. 1972) and also more recently for different types of permeable pavements that provide significant surface runoff and peak flow rate reductions compared with standard asphalt (Collins et al. 2008). But like other porous surfaces, porous asphalt usually undergoes clogging or blockage problems (Scholz and Grabowiecki 2007; Haselbach 2010; Fassman and Blackbourn 2010).

The clogging of pavements, with the consequent reduction of infiltration rates, may occur with more probability in the surface layer and in the separation geotextile (Legret et al. 1996; Rommel et al. 2001). Therefore, studies that assure a suitable infiltration capacity of these two layers throughout the operational life of the pavement are necessary.

Steady-state flow through porous media is governed by the Navier-Stokes equations, but it is a reasonable approximation to consider that the flow through porous concrete and asphalt pavements is laminar and so it is possible to apply Darcy's law (Sansalone et al. 2008; Charbeneu et al. 2010).

Suitable designs of permeable pavements have a permeability of the pavement layers that increases with depth (Pratt et al. 2002; Haselbach 2010). With this design, when the 
water passes the surface, there is no obstacle preventing quick infiltration. Moreover, the surface layer acts like a sieve, preventing silt entering the porous pavement and facilitating the cleaning work. This was proved by Haselbach (2010) for pervious concrete, analysing the effect of clay suspensions in cores taken from three field placements.

However, in the past, the porous asphalt designs were as permeable as possible; that is to say, with the highest possible void percentages in order to slow down clogging (Membrillo Medrano 1994). In fact, the larger void percentage meant increasing the size and penetration of the sediments in the mixture, so that clogging became deeper and more difficult to clean. After many problems with surface blockage, modern porous asphalt is designed in two layers with different void percentages. Bendtsen et al. (2005) test three combinations of two layers of porous asphalt with void percentages that increase with depth in order to find a solution for the clogging problem that limits the useful lifetime of this permeable surface to two years in Denmark.

In France, Legret (2001) analyses the clogging mechanisms in porous asphalt, stating an operational life of three years without maintenance. The particles that clog surfaces are mainly sands located in the first two centimetres of the permeable surface. One of the contributions of the study is the division into two kinds of particles that block porous surfaces: primary cloggers (mineral particles) and secondary cloggers (finer particles that can be affected by water). The repeated wet-dry cycles make secondary cloggers act as binders for the primary ones, increasing cohesion in sediments and making cleaning difficult. This leads to the reduction of permeability over time without brushing (Legret 2001). In the United States, laboratory and field results indicate that rejuvenation methods such as vacuum sweeping, or pressure washing, can substantially restore the performance of pervious concrete pavements (Chopra et al. 2010). 
In Sweden, Hogland et al. (1987) verified that the risk of clogging and blockage of the PPS is higher in the presence of construction work around the site. In this sense, Schlüter and Jefferies (2005) state that runoff coming from construction sites has the greatest effect on the operational life of infiltration systems because of the amount of sediments that it drags. Surface infiltration measurement carried out by Fassman and Blackbourn (2010) at four sites in New Zealand confirmed that surrounding land uses have more influence on permeable pavement blockage than traffic load. Consequently, a scenario with sediments from construction work containing primary and secondary cloggers under wet-dry cycles is the worst possible scenario for porous asphalts such as PPS.

Shackel (1997) studied the infiltration capacity of permeable paving stone surfaces and the structural strength of the subbase using a line of sprinklers as a rainfall simulator, controlling the intensity through a valve and a flow meter. Later, the studies carried out in Coventry University (Davies et al. 2002) and in the University of South Australia (Rommel et al. 2001) continued with this, testing permeable pavements (paving stones, bed layer and geotextile) under conditions of rain and clogging in laboratory conditions. Mainly based in Davies et al. (2002), the Cantabrian Fixed Infiltrometer (CF Infiltrometer) was developed in Spain (Rodríguez et al. 2005 and Castro et al. 2007). The runoff resistance test carried out with the CF Infiltrometer consists in applying increasing runoffs to a permeable surface, varying the slope to quantify how the drainage path varies with the slope and the input runoff volume (González-Angullo et al. 2008).

Valavala et al. (2006) tested paving stones made with porous concrete with void percentages between 16 and 27\%, varying the surface slope between 2 and $10 \%$ and the type of sand where the paving stones are laid. Three main conclusions were obtained by 
this study: runoff increases as the slope increases, the base permeability may become limiting, and a new pavement of this type hardly produces runoff.

With porous asphalt, apart from some field studies carried out by Fernández-Barrera et al. (2008), there are some laboratory studies about clogging effects on permeability (Pérez Jiménez et al. 1985; Pérez Jiménez and Calzada Pérez 1990; Tan et al. 2002). These laboratory studies use different types of permeameters, but not rain or runoff simulation.

This paper presents the laboratory study of the infiltration capacity of porous asphalt using the CF Infiltrometer and a methodology based on the one developed by Rodríguez et al. (2005) and improved by Castro et al. (2007) and Gónzalez-Angullo et al. (2008) for the study of permeable surfaces.

The objectives of this study are to obtain graphs that show the infiltration capacity of the porous asphalt with different gradients, for different clogging scenarios, and to propose a regression equation that explains the infiltration capacity of PPS with porous asphalt.

\section{Methodology}

\section{CF Infiltrometer}

The tests were carried out in the Roads Laboratory of the Civil Engineering School in Santander, using the CF Infiltrometer and the test methodology described below. The CF Infiltrometer (Figure 1) is based on the infiltrometer used by Davies et al. (2002) to measure the infiltration of surface runoff through permeable pavements built with concrete blocks. With the CF Infiltrometer it is possible to test the infiltration capacity 
square test pieces of permeable pavements of $50 \mathrm{~cm}$ side with 5 variables: type of surface, surface slope, clogging scenario, rainfall on the surface and runoff inflow. Thanks to the six chambers located in the lower part of the equipment (Figure 1), it is possible to measure the quantity of water infiltrated every $10 \mathrm{~cm}$ of the surface and the final surface runoff after a length of $50 \mathrm{~cm}$ of permeable surface.

\section{Test Pieces}

Each PPS model (geotextile, granular base and porous asphalt surface) was placed in a square wooden frame, the perimeter was sealed and the clogging scenario was simulated (Figure 2). The bottom geotextile chosen for these tests was a non woven needlepunched geotextile made of polyester, with $150 \mathrm{~g} / \mathrm{m} 2$ and a permeability rate to water flow of 110 1/m2s. The geotextile was laid on a mesh, within the square frame. The geotextile piece was $600 \mathrm{~mm}$ long and wide, so that the extra $50 \mathrm{~mm}$ went up the edges of the wooden frame (Figure 2a). Then, the granular base was hand compacted and levelled on the geotextile with a height of $50 \mathrm{~mm}$ (Figure $2 \mathrm{~b}$ ). The chosen aggregate was crushed limestone grit between $4 \mathrm{~mm}$ and $8 \mathrm{~mm}$. Next, one square slab of porous asphalt was placed on the granular base (Figure $2 \mathrm{c}$ ).

Six square slabs of porous asphalt with $50 \mathrm{~cm}$ side and $10 \mathrm{~cm}$ height were prepared for this study. They were compacted in laboratory after a second warming of the bituminous mixture fabricated in a hot mix asphalt plant. The porous asphalt was made with modified bitumen BM 3b (PG-3 2007) and ophite aggregates adjusted to the opengraded PA-12 (PG-3 2007) particle size (Table 1).

Table 2 shows the characteristics of the porous asphalt test pieces. It may be seen how the calculated voids in the mixture vary from $27.8 \%$ to $32.9 \%$. 
The time results of the surface tests with the LCS Permeameter are shown in Table 2 with the associated void percentages in the mixture according to the equation recommended by the Spanish Ministry of Public Works and Urbanism (MOPU 1987) and employed by Fernández-Barrera et al. (2008):

$$
\operatorname{Ln} H=4.071-0.305 \operatorname{Ln} T
$$

where $H$ is the voids in mixture $\%$ and $T$ is the time result of the LCS Permeameter. The experimental voids in mixture vary from $20.17 \%$ to $30.03 \%$, a larger variarion than in the calculated voids in mixture.

Comparing the calculated and experimental voids in mixture (Table 2), it may be seen that the test pieces 1,2 and 3 show higher calculated values than those obtained from the infiltration time with the LCS Permeameter. The calculated void percentage corresponds to the whole test piece while the experimental void percentage corresponds mainly to the surface. The manufacturing procedure in a $10 \mathrm{~cm}$ high layer causes segregation in the test pieces that makes permeability slightly decrease from the upper face to the lower face. On the one hand, test pieces 1,2 and 3 were turned over before the measurement with the LCS Permeameter and later with the CF Infiltrometer in order to obtain an increasing permeability with depth (better conditions under clogging). On the other hand, test pieces 4, 5 and 6 were tested with the LCS Permeameter and later with the CF Infiltrometer without turning them over in order to conserve the decreasing permeability with depth (worse conditions under clogging).

\section{Clogging Scenarios}

The sediment used to simulate the clogging conditions was crushed construction waste: bricks, glass, metal, wood, etc (Figure 2d). This sediment included organic matter smaller than $2 \mathrm{~mm}$ ( $3 \%$ according to the potassium dichromate method or $5 \%$ according 
to loss on ignition). The size distribution of sediment particles was similar to that used by Davies et al. (2002), Castro et al. (2007) and González-Angullo et al. (2008), containing primary and secondary cloggers.

Three clogging scenarios were evaluated using the CF Infiltrometer:

- Scenario 1- new pavement without sediment on the surface.

- Scenario 2- pavement with maintenance consisting in silt brushing.

- Scenario 3-pavement without maintenance.

Each of the six test pieces was tested twice, newly placed (scenario 1) and under one clogging scenario (2 or 3$)$, which combined with five different slopes $(0 \%, 2 \%, 5 \%, 8 \%$ and $10 \%$ ) make a total of sixty tests, each one repeated three times to obtain an average. In scenario 2 and scenario 3, the voids in the surface were filled with 500 grs of sediment $(2 \mathrm{~kg} / \mathrm{m} 2)$ and then hand compacted (Figure 2d). After this, in scenario 2, the excess sediment was brushed off the surface. The resulting sediment was different for each test piece: $0.56 \mathrm{~kg} / \mathrm{m} 2$ for test piece $1 ; 0.92 \mathrm{~kg} / \mathrm{m} 2$ for test piece 2 and $0.76 \mathrm{~kg} / \mathrm{m} 2$ for test piece 3 . The average is $0.75 \mathrm{~kg} / \mathrm{m} 2$ with $22.3 \%$ voids on surface. The aim of scenario 2 is to simulate just one specific maintenance action consisting in brushing the clogged surface. This is the easiest maintenance possible, so any other more complete action would obtain better results in the renovation of the surface.

In scenario 3, there was no type of brushing and the sediment load tested was $2 \mathrm{~kg} / \mathrm{m} 2$ for the test pieces 4,5 and 6 . The aim of this scenario is to simulate extreme conditions of clogging that most real porous asphalt pavements will never reach, even under longterm use (15-20 years), but that in some locations could be reached after 2-3 years depending on the silt contribution (Bendtsen et al. 2005, Legret 2001). 


\section{Rain and Runoff Simulation}

The rain event simulated in each experiment lasted 30 minutes. The first 10 minutes of simulated rain and runoff were used to wet the test piece. Then, the measurement period of 20 minutes began. The volumes of water collected in the six chambers at the end of this 20 minute period constitute the results for each combination of variables tested, representing the cumulative infiltration and the runoff generation. These results can be expressed in percentages with respect to the total volume of water.

Under relatively low rainfall conditions, the infiltration opportunity time and the interactive infiltration rate increase (Sheldon and Fiedler 2008). Rain intensity was fixed around $47 \mathrm{~mm} / \mathrm{h}$ in this study to avoid this effect and to obtain conservative results about the infiltration capacity under severe storm events. To characterize the infiltration capacity of porous asphalt without the effect of the pore space blockage in the runoff generation, scenario 1 was studied for the 6 porous asphalt slabs under this rain intensity.

This rain intensity was applied as runoff coming from an equivalent impervious surface (runoff simulation) and also directly over the test piece (rainfall simulation). The runoff is simulated by a perforated pipe over a plastic ramp at the beginning of the surface and the direct rainfall simulation is produced by 75 adjustable bubblers $(0-40$ litres per hour). These are distributed in 5 lines of 15 bubblers each placed $30 \mathrm{~cm}$ over the $0.25 \mathrm{~m} 2$ test pieces. The droplet diameter produced is around $3.5 \mathrm{~mm}$ and its theoretical kinetic energy is $5.6 \cdot 10^{-4} \mathrm{~J}$.

Both flows, rainfall and runoff, were verified by direct water collection and measurement at the beginning and at the end of each one of the 60 tests. The mean value 
of the simulated intensity was $47.68 \mathrm{~mm} / \mathrm{h}$ for the runoff flow with a standard deviation of 3.03; and $47.91 \mathrm{~mm} / \mathrm{h}$ for the rainfall simulation with a standard deviation of 2.88 .

\section{Results and discussion.}

\section{Scenario 1}

Half of the tests performed with the CF Infiltrometer (thirty tests) correspond to scenario 1 of newly placed surface. The six test pieces were characterised in this scenario, gathering the average results in two groups: Test pieces 1, 2 and 3 (increasing infiltration capacity with depth) and test pieces 4, 5 and 6 (decreasing infiltration capacity with depth). The results obtained and the quadratic estimates of the infiltrated water percentage in relation to the length covered on the permeable surface for each group of test pieces are shown in Figure $3 \mathrm{a}$ and Figure $3 \mathrm{~b}$.

The infiltrated water percentage is an expression of the cumulative infiltration $(\mathrm{F})$ and its quadratic estimation enables a linear expression of the infiltration rate (f) to be derived. This expression depends on the moisture content in the permeable pavement $(\theta)$ represented by the length covered on the permeable surface, considering that when the length increases, the total amount of water received (adding rainfall and runoff) and consequently the moisture content in the permeable water decreases.

Test pieces of porous asphalt whose permeability increases with depth are able to infiltrate $98 \%$ of the total water used in the test with $0 \%$ slope and $91 \%$ with $10 \%$ slope. However, test pieces of porous asphalt whose permeability decreases with depth are able to infiltrate $94 \%$ of water with $0 \%$ slope and $83 \%$ with $10 \%$. There is a slight difference, which is not decisive. Considering the averages, a length of $50 \mathrm{~cm}$ of newly placed porous asphalt is able to infiltrate $96 \%$ of the water used in the test with $0 \%$ slope and $87 \%$ with $10 \%$ slope. Observing the estimations, the difference is clear with a 
slightly worse infiltration capacity in the case of a porous asphalt test pieces with decreasing permeability with depth (Figure $3 b$ ). All estimations pass through point $(0.0)$, corresponding to the beginning of the permeable surface, where the infiltration is zero in any case. The lowest coefficient of determination $\left(\mathrm{R}^{2}\right)$ is 0.9478 in Figure 3a and 0.9198 in Figure 3b, both with 2\% slope.

Comparing these results with a newly placed real-life porous asphalt pavement, the influence of a bad design or an excessive slope can reduce the infiltration capacity of the surface even without clogging.

\section{Scenario 2}

Fifteen tests were performed under scenario 2 with simulated maintenance. The three test pieces chosen for this scenario were 1, 2 and 3 (better conditions under clogging). The results obtained and the quadratic estimations of the infiltrated water percentage in relation to the length of the permeable surface are shown Figure $3 \mathrm{c}$. In this case, the lowest $\mathrm{R}^{2}$ is 0.9441 with $2 \%$ slope. Both results and estimations are very similar to the ones obtained without sediments (Figure 3a). This means that the increasing void percentages with depth and the superficial brushing are enough to recover the initial infiltration capacity of the porous asphalt.

The associated cost of the maintenance depends mainly on the location and silt contribution. However, a correct design and a specific maintenance action after clogging are always cheaper than the complete replacement, which would be the last option.

Comparing the results presented on Figure $3 a$ and Figure $3 b$, the infiltration capacity is slightly better in the second one for the case of high slopes ( $8 \%$ and $10 \%)$. This would imply a slight beneficial effect of a light sediment load $(0.75 \mathrm{~kg} / \mathrm{m} 2)$ for increasing 
infiltration in high slopes. The reason could be that the sediment would hold water, reducing the runoff velocity, increasing the infiltration opportunity time.

Consequently, in a real-life pavement, the presence of a slight amount of silt on the surface is not as critical as might be thought.

\section{Scenario 3}

Finally, fifteen tests were performed with the CF Infiltrometer simulating scenario 3 with clogged surface without maintenance. The three test pieces selected for the study of the clogged surface were test pieces 4,5 , and 6 (higher void percentages on the surface).

The results and estimations corresponding to each one of the slopes tested with a clogged surface are shown in Figure $3 \mathrm{~d}$. The infiltrated percentages at $50 \mathrm{~cm}$ vary between $76 \%$ for the $0 \%$ slope case and $63 \%$ for the $10 \%$ slope case. The lowest $\mathrm{R}^{2}$ is 0.9229 for the case of a $2 \%$ slope.

Comparing Figure $3 \mathrm{~d}$ with the previous ones, it can be observed that all the curves from scenario 3 present concavities. This effect may be caused by the increase in the sediment load on the surface or/and by the increase of the surface slope. So, even without clogging problems, the porous bituminous mixture can behave as if it were slightly blocked when the surface slope greater than or equal to $5 \%$.

Neglecting the slope influence, $2 \mathrm{~kg} / \mathrm{m} 2$ of silt does not critically reduce the infiltration capacity. Therefore, in a real-life porous asphalt pavement the clogging scenario would correspond to a greater amount of silt. 


\section{Empirical Model for Porous Asphalt}

It was possible to carry out a regression analysis considering the results of cumulative infiltration measured in each one of the 5 chambers during the 3 repetitions of the 60 tests, which provided a total of 900 points. The objective was to obtain the infiltrated water ( $\%$ of the total water used in each test) based on the length of porous asphalt $(\mathrm{cm})$, the clogging scenario $(\mathrm{kg} / \mathrm{m} 2)$ and the surface slope $(\%)$. These three explanatory variables are simultaneously significant at the $95 \%$ level, as the $\mathrm{F}$ test of Fisher Snedecor provides a p-value less than 0.05. Moreover, all variables are significant individually at $95 \%$ with the contrast $\mathrm{p}$-values of the $\mathrm{T}$ statistic less than 0.05 . The elimination of the independent value from the model was decided after checking that the value of the $\mathrm{T}$ statistic for it was clearly lower than the three explanatory variables, and also considering the physical justification that there should not be infiltration when the length is $0 \mathrm{~cm}$. The authors propose the following regression equation after evaluating different transformations of the variables:

$$
I=23.403 \cdot \operatorname{Ln}(L)-5.095 \cdot C^{2}-4.749 \cdot S
$$

where $I$ is the infiltration $(\%), L$ is the length $(\mathrm{cm}), C$ is the clogging scenario $\left(\mathrm{kg} / \mathrm{m}^{2}\right)$ and $S$ is the surface slope $(\%)$.

The model was tested to validate the regression analysis assumptions and it has a $\mathrm{R}^{2}=0.860$. The explanatory variables considered had no correlation with each other so they could be considered independent. The diagnosis of collinearity also had a condition index value less than 30 so there was no collinearity. The Durbin Watson statistic had a value of 1.435 , indicating no autocorrelation problems with the residues. Furthermore, a diagnosis by-case did not find any outlier located farther than three standard deviations from the estimation. The analysis of residues in comparison with the predicted values 
showed no heteroskedasticity problems apart from the clear ranges of the variables tested. In addition, the scatter plot of residues indicated their normality.

The representations of the proposed model can be done introducing a value for any of the explanatory variables. For example, the graphic model for porous asphalt with $2 \%$ surface slope is shown in Figure 4. Compared to the previous analysis of the results (Figure 3), this is a conservative model. According to the model, in this particular case a $50 \mathrm{~cm}$ strip of porous asphalt is capable of infiltrating a maximum of over $80 \%$ of the water used in the test without silt on the surface and a minimum of $0 \%$ with $4 \mathrm{~kg} / \mathrm{m}^{2}$ of silt on the surface.

This empirical model for porous asphalt is limited to the interpretation of the results obtained in the laboratory with the CF Infiltrometer, giving only a conservative impression of what could happen in a real porous asphalt pavement.

\section{Conclusions}

The main objective of this study was to propose a regression equation that explains the infiltration capacity of PPS with porous asphalt. With this aim, several porous asphalt slabs were tested in controlled laboratory conditions with the CF Infiltrometer, varying gradients and clogging scenarios.

The main laboratory results indicate that, even without clogging problems, the porous bituminous mixture can behave as if it were slightly blocked when the surface slope is greater than or equal to $5 \%$.

However, a slight amount of silt on the surface offers a beneficial effect with slope, retaining the runoff flow and improving the infiltration opportunity time. 
According to the results, in a real-life pavement, a suitable design of a porous

bituminous mixture, with an increasing void percentage with depth, along with a timely superficial brushing are enough to ensure and maintain a suitable infiltration capacity.

Finally, a regression equation has been proposed to estimate the infiltrated water $(\%$ of the total water used in each test) based on the length of porous asphalt $(\mathrm{cm})$, the clogging scenario $(\mathrm{kg} / \mathrm{m} 2)$ and the surface slope $(\%)$. This empirical model is limited but it can provide a conservative estimate of what could happen in a real porous asphalt pavement, resulting in a $0 \%$ of infiltration with a clogging scenario with $4 \mathrm{~kg} / \mathrm{m} 2$ of silt in the surface.

Future work will include validating this empirical model with a theoretical approach and calibrating it through the analysis of real-life porous asphalt pavements.

\section{Acknowledgments}

This paper was possible thanks to the research project entitled "Development of new structures of pavements for the biodegradation of hydrocarbons (FIDICA)" (REN200305278/TECNO) developed by the Construction Technology Research Group (GITECO) of the University of Cantabria, financed by the Spanish Ministry of Science and Technology with funds of the PGE (General Budget of the State) and of the FEDER (European Funds for Regional Development), as a part of the "Projects of Scientific Research and Technological Development" programme. 


\section{Notation}

$H=$ the voids in mixture of the porous asphalt (\%).

$T=$ time result of the LCS Permeameter.

$I=$ cumulative infiltration using CF Infiltrometer (\%)

$L=$ suface length $(\mathrm{cm})$

$C=$ clogging scenario $\left(\mathrm{kg} / \mathrm{m}^{2}\right)$

$S=$ surface slope $(\%)$. 


\section{References}

Bendtsen H., Andersen B., Ruth B., Phillips J., Dunning M. (2005). Noise-reducing pavements for highways and urban roads - State of the art in Denmark. Asphalt paving technology: Association of Asphalt Paving Technologists - Proceedings of the Technical Sessions 74, pp 1085-1105.

Castro D., González-Angullo N., Rodríguez J., Calzada M.A. (2007) The influence of pavingblock shape on the infiltration capacity of permeable paving. Land Contamination \& Reclamation, 15 (3), pp. 335-344

Charbeneau R.J., Klenzendorf J.B., Barrett M.E. (2010) Methodology for determining laboratory and in situ hydraulic conductivity of asphalt permeable friction course. Journal of Hydraulic Engineering, 137 (1), pp. 15-22.

Chopra M., Kakuturu S., Ballock C., Spence J., Wanielista M. (2010) Effect of rejuvenation methods on the infiltration rates of pervious concrete pavements. Journal of Hydrologic Engineering, 15 (6), pp. 426-433.

Collins K.A., Hunt W.F., Hathaway J.M. (2008) Hydrologic comparison of four types of permeable pavement and standard asphalt in eastern North Carolina. Journal of Hydrologic Engineering, 13 (12), pp. 1146-1157.

Davies J.W., Pratt C.J., Scott M.A. (2002) Laboratory study of permeable pavement systems to support hydraulic modelling. Proceedings of the 9th International Conference on Urban Drainage (9ICUD). September 8-13. Portland, Oregon. ISBN: 0784406448

Fernández-Barrera A.H., Castro-Fresno D., Rodríguez-Hernández J., Calzada-Pérez M.A. (2008) Infiltration Capacity Assessment of Urban Pavements Using the LCS Permeameter and the CP Infiltrometer. Journal of Irrigation and Drainage Engineering, 134 (5), pp. 659-665

Fassman E. A., Blackbourn S. (2010) Urban runoff mitigation by a permeable pavement system over impermeable soils. Journal of Hydrologic Engineering, 15 (6), pp. 475-485.

González-Angullo N., Castro-Fresno D., Rodríguez J., Davies J.W. (2008) Runoff infiltration to permeable paving in clogged conditions. Urban Water Journal, 5 (2). pp. 117-124.

Grover W.C., Hoiberg A.J., Haigh T.I. (1972) Investigation of porous pavements for urban runoff control. Water Pollution Control Research Series: 11034 DUY. US Government Printing Office, Washington DC.

Haselbach L. M. (2010) Potential for clay clogging of pervious concrete under extreme conditions. Journal of Hydrologic Engineering, 15 (1), pp. 67-69.

Hogland W., Niemczynowicz J., Wahlman T. (1987) The unit superstructure during the construction period. Science of the Total Environment, 59. pp. 411-424. 
Legret M. (2001) Pollution et impact d'eaux de ruissellement de chaussées (Pollution and impact of the runoff of roads). Routes CR 27 Études et Recherches des Laboratoires des Ponts et Chaussées. Paris: Laboratoire Central des Ponts et Chaussées (LCPC).

Legret M., Colandini V., Le Marc C. (1996) Effects of a porous pavement with reservoir structure on the quality of ruoff water and soil. Science of the Total Environment, 189/190. pp. 335-340

Membrillo Medrano, J. M. (1994) Técnicas especiales de conservación de firmes flexibles (Special techniques for the conservation of flexible pavements). $V$ Jornadas de Conservación de Carreteras. Los contratos de conservación. May 24-27. Granada, Spain. pp. 279-296

MOPU (1987) Mezclas bituminosas porosas (Porous bituminous mixtures). Madrid: Secretaría General Técnica, Centro de Publicaciones, Ministerio de Obras Públicas y Urbanismo. ISBN: 84-7433-491-8

Pérez Jiménez F.E., Calzada Pérez M.A., Gonzalez Bengochea R. (1985). Mezclas bituminosas porosas: Estudio en laboratorio de sus características permeables y resistencia a la abrasión (Porous Bituminous Mixtures: Laboratory study of permeability and abrasion resistance). Memoria de la Cátedra de Caminos y Aeropuertos de la Escuela Técnica Superior de Ingenieros de Caminos, Canales y Puertos de Santander para el Ministerio de Obras Públicas y Urbanismo (MOPU).

Pérez Jiménez F.E., Calzada Pérez M.A. (1990) Analysis and Evaluation of the Performance of Porous Asphalt: The Spanish Experience. Surface characteristics of roadways: international research and technologies. Papers of the First International Symposium on Surface Characteristics, June 8-9, 1988, Pennsylvania: Meyer/Reichert. ASTM STP 1031. ISBN: 0-8031-1391-9

PG-3 (2007) Pliego de prescripciones técnicas generales para obras de carreteras y puentes (Document of general technical recommendations for road and bridge construction work). Madrid: Ediciones Liteam (Gerardo Bustos Pretel y Enrique Pérez Ibáñez). Colección normativa técnica. ISBN 13: 978-84-95596-88-8

Pratt C., Wilson S., Cooper P. (2002) Source control using constructed pervious surfaces. Hydraulic, structural and water quality performance issues. London: CIRIA. CIRIA C582, RP637; ISBN: 0860175820

Rodríguez J., Castro D., Calzada M.A., Davies J.W. (2005) Pervious Pavement Research in Spain: Structural and Hydraulic issues. Proceedings of the 10th International Conference on Urban Drainage (10ICUD). August 21-26. Copenhagen, Denmark.

Rommel M., Rus M., Argue J., Johnston L, Pezzaniti D. (2001) Carpark with 1 to 1 (impervious/permeable) paving: performance of Formpave blocks. NOVATECH'2001, 
Sustainable Techniques and Strategies in Urban Water Management, $4^{\text {th }}$ International Conference. June 20-27. Lyon, France. pp. 807-814.

Sansalone J., Kuang X., Ranieri V. (2008) Permeable Pavement as a Hydraulic and Filtration Interfacefor Urban Drainage. Journal of Irrigation and Drainage Engineering, 134 (5), pp. 666-674.

Scholz M., Grabowiecki P. (2007) Review of permeable pavement Systems. Building and Environment, 42 (11). pp. 3830-3836.

Shackel B. (1997) Water Penetration and Structural Evaluations of Permeable Eco-Paving. Betonwerk und Fertigteil-Technik/Concrete Precasting Plant and Technology, 63 (3). pp 110-118.

Sheldon S.A. and Fiedler F.R. (2008) Direct numerical simulation of hortonian runoff resulting from heterogeneous saturated hydraulic conductivity. Journal of Hydrologic Engineering, 13(10), 948-959.

Schlüter W., Jefferies C. (2005) The real issues with in-ground SUDS in Scotland. Proceedings of the 10th International Conference on Urban Drainage (10ICUD). August 21-26. Copenhagen, Denmark.

Tan S.A., Fwa T.F., Guwe V.Y.F. (2000) Laboratory measurements and analysis of clogging mechanism of porous asphalt mixes. Journal of Testing and Evaluation, 28 (3). pp. 207213.

Valavala S., Montes F., Haselbach L.M. (2006) Area-Rated Rational Coefficients for Portland Cement Pervious Concrete Pavement. Journal of Hydrologic Engineering - ASCE. MayJune. pp. 257-260. 


\section{List of Figures}

Figure 1. Cantabrian Fixed Infiltrometer (CF Infiltrometer).

Figure 2. PPS model with porous asphalt: (a) geotextile layer, (b) granular base, (c) porous surface with sealed perimeter and (d) clogging scenario.

Figure 3. Estimations of percentage of infiltrated water in relation to the distance covered for each slope in the case of: a) newly placed pavement in test pieces 1, 2 and 3, b) newly placed pavement in test pieces 4, 5 and 6, c) pavement with medium maintenance level in test pieces 1, 2 and 3 and d) clogged pavement in test pieces 4,5 and 6 .

Figure 4. Graphic model for porous asphalt infiltration capacity with $2 \%$ surface slope. 


\section{List of tables}

Table 1. Particle size of the porous asphalt aggregates for a PA-12 mixture [21].

Table 2. Characteristics of the porous asphalt test pieces. 

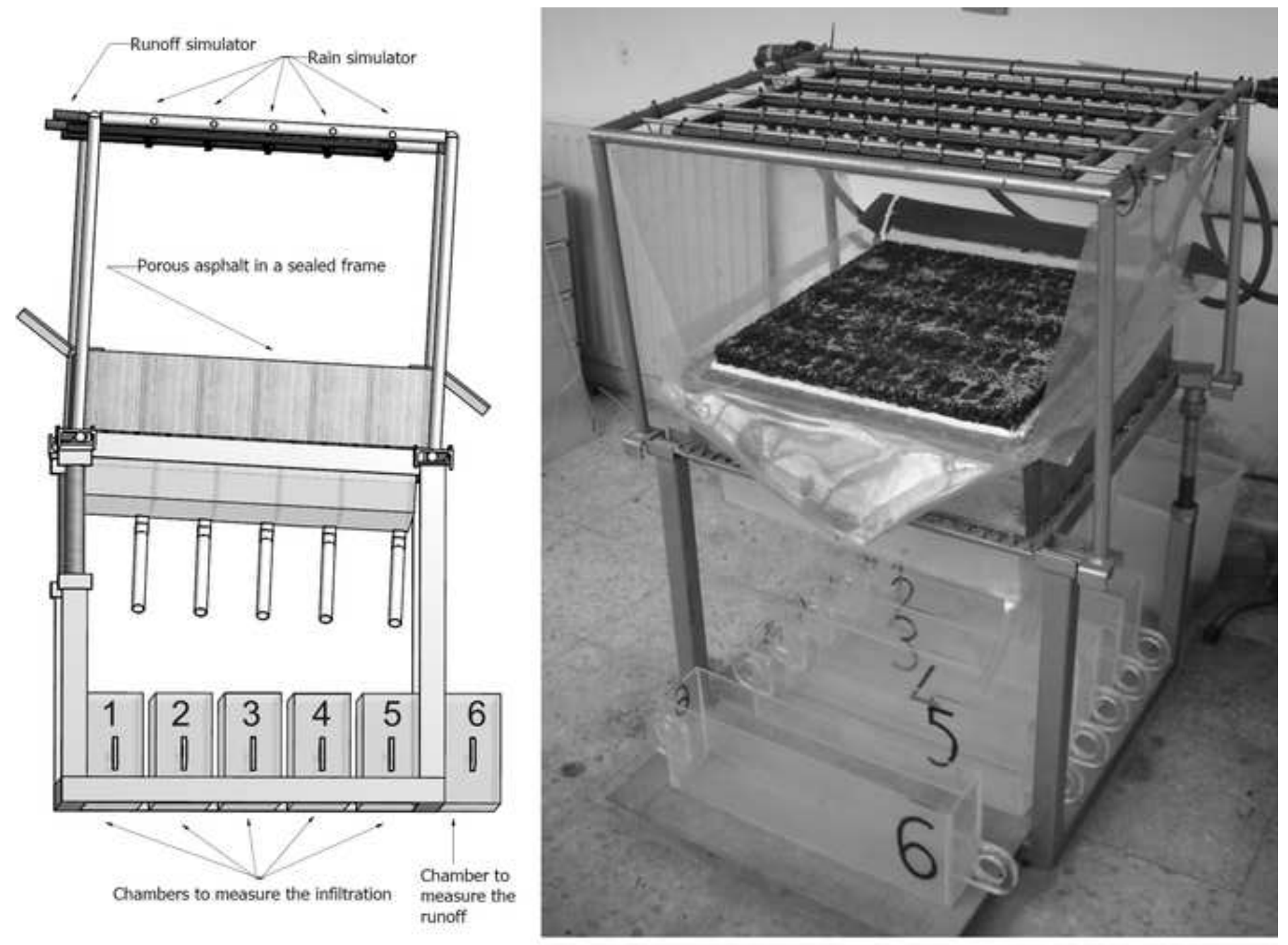

Figure 1. Cantabrian Fixed Infiltrometer (CF Infiltrometer). 

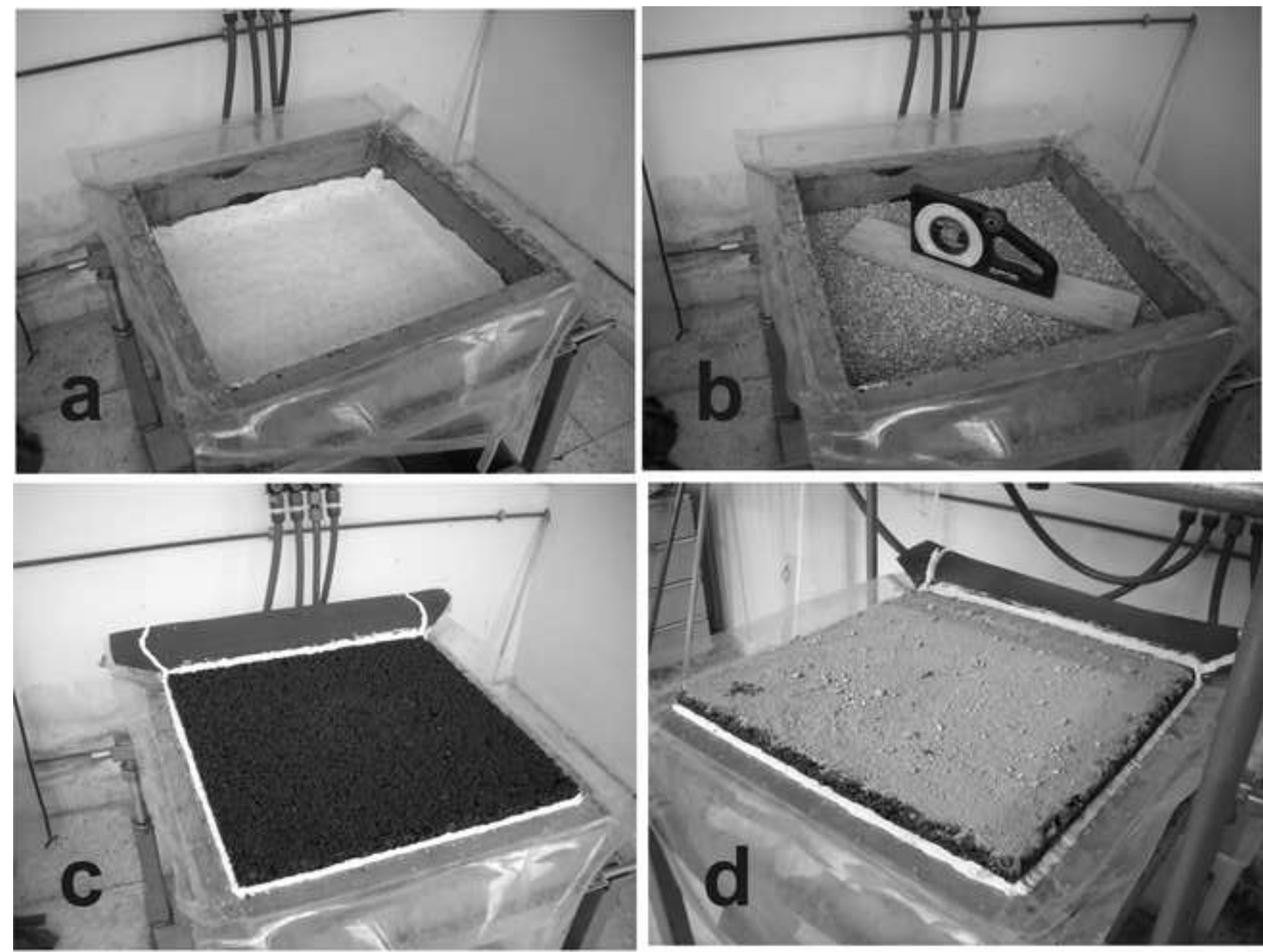

Figure 2. PPS model with porous asphalt: (a) geotextile layer, (b) granular base, (c) porous surface with sealed perimeter and (d) clogging scenario. 

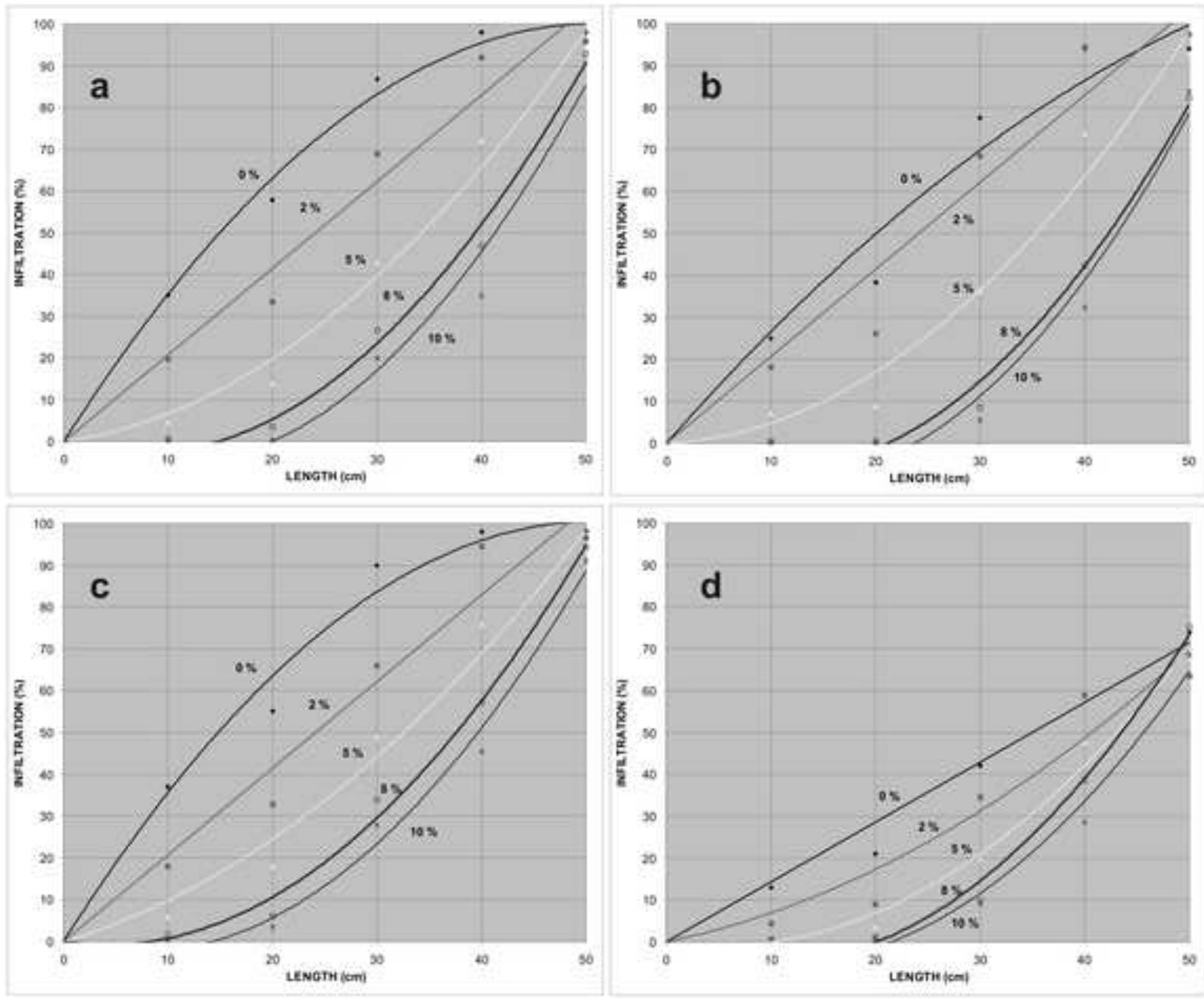

Figure 3. Estimations of percentage of infiltrated water in relation to the distance covered for each slope in the case of: a) newly placed pavement in test pieces 1,2 and 3, b) newly placed pavement in test pieces 4,5 and $6, \mathrm{c}$ ) pavement with medium maintenance level in test pieces 1,2 and 3 and d) clogged pavement in test pieces 4,5 and 6 . 


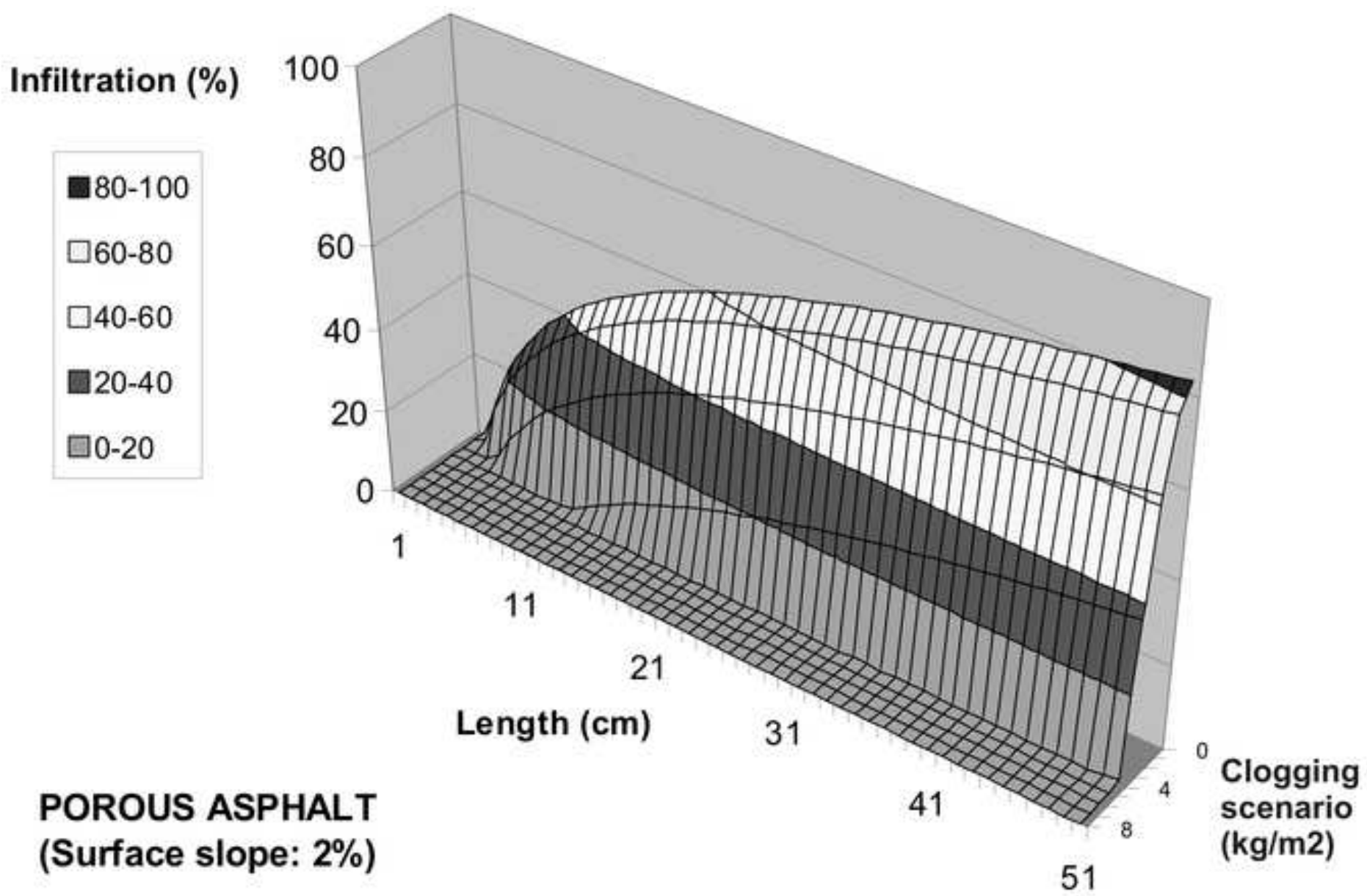

Figure 4. Graphic model for porous asphalt infiltration capacity with $2 \%$ surface slope 


\begin{tabular}{lccccccc}
\hline Particle size (mm) & $\mathbf{2 0}$ & $\mathbf{1 2 . 5}$ & $\mathbf{8}$ & $\mathbf{4}$ & $\mathbf{2}$ & $\mathbf{0 . 5}$ & $\mathbf{0 . 0 6 3}$ \\
\hline Percentage passing (\%) & 100 & $70-100$ & $38-62$ & $13-27$ & $9-20$ & $5-12$ & $3-6$ \\
\hline
\end{tabular}

\section{Accepted Manuscript Not Copyedited}


Journal of Hydrologic Engineering. Submitted July 17, 2010; accepted July 25, 2011; posted ahead of print July 27, 2011. doi:10.1061/(ASCE)HE.1943-5584.0000480

\begin{tabular}{cccccc}
\hline Test piece & $\begin{array}{c}\text { Density } \\
(\mathrm{kg} / \mathrm{m} 3)\end{array}$ & $\begin{array}{c}\text { Calculated } \\
\text { void } \\
\text { percentage } \\
(\%)\end{array}$ & $\begin{array}{c}\text { Tested surface with } \\
\text { the LCS Permeameter }\end{array}$ & $\begin{array}{c}\text { Average time } \\
\text { between marks } \\
(\mathrm{s})\end{array}$ & $\begin{array}{c}\text { Experimental void } \\
\text { percentage }(\%)\end{array}$ \\
\hline 1 & 1,920 & 28.06 & LOWER face & 33.06 & 20.17 \\
\hline 2 & 1,790 & 32.91 & LOWER face & 15.74 & 25.29 \\
\hline 3 & 1,850 & 30.94 & LOWER face & 27.36 & 21.36 \\
\hline 4 & 1,910 & 28.63 & UPPER face & 11.11 & 28.12 \\
\hline 5 & 1,930 & 27.84 & UPPER face & 8.96 & 30.03 \\
\hline 6 & 1,910 & 28.49 & UPPER face & 13.78 & 26.34 \\
\hline
\end{tabular}

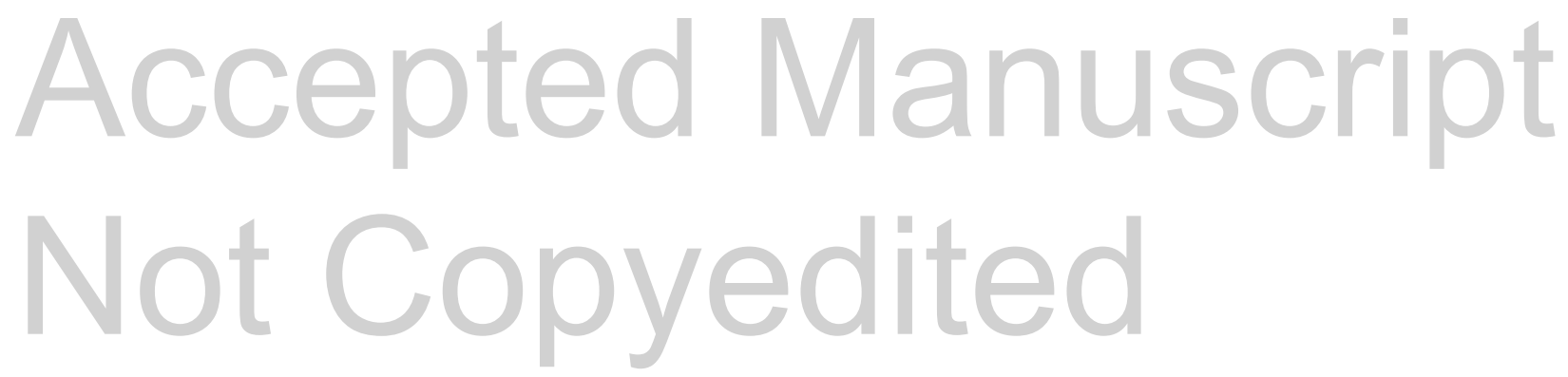

